\title{
The Current Constraints and Opportunity of Beekeeping in Ethiopia: A Review
}

\author{
Siraj Sh. Mohammed ${ }^{1, *}$, Abdi Hassen ${ }^{2}$ \\ ${ }^{1}$ Meta Agricultural Office, School of Animal and Range Sciences, Haramaya University, Haramaya, P. O.Box 138, Dire Dawa, Ethiopia. \\ ${ }^{2}$ East Hararghe, Meta Agricultural Office, College of Agriculture and Environmental Sciences, Africa Center of Excellence for Climate \\ Smart Agriculture and Biodiversity Conservation, Department of Climate Smart Agriculture, Haramaya University, Haramaya, Ethiopia.
}

How to cite this paper: Siraj Sh. Mohammed, Abdi Hassen. (2021). The Current Constraints and Opportunity of Beekeeping in Ethiopia: A Review. Advance in Biological Research, 2(1), 8-15.

DOI: 10.26855/abr.2021.12.001

Received: November 15, 2021

Accepted: December 8, 2021

Published: December 17, 2021

Corresponding author: Siraj Sh. Mohammed, Meta Agricultural Office, School of Animal and Range Sciences, Haramaya University, Haramaya, P. O.Box 138, Dire Dawa, Ethiopia.

Email: sirajmhd2021@gmail.com

\begin{abstract}
The goal of this article was to summarize beekeeping's limits and potential in Ethiopia. Beekeeping techniques and some of the roles of this sector in Ethiopia's economy will be covered in this article. Currently, there are three broad classifications of honey production systems in Ethiopia; these are traditional (forest and backyard), transitional (intermediate), and modern (frame beehive) systems. Despite the challenges and constraints, Ethiopia has the largest bee population in Africa with over 10 million bee colonies, of which 5 to 7.5 million are hived while the remaining exists in the wild. The country has the potential of producing up to 500,000 tons of honey per annum. But currently, the production is limited to 53,000 to 58,000 tons of honey. Ethiopia has even bigger potential than the current honey production due to the availability of plenty of apicultural resources such as natural forests with adequate apiculture flora, water resources, and a high number of existing bee colonies. Lack of well-trained manpower, honey bee pests and diseases, the high cost and limited availability of modern beekeeping equipment, and improper use of pesticides are some of the major constraints that prevent Ethiopian beekeeping from reaching its full production potential. To significantly improve the beekeeping sub-sector, the government and relevant development partners must collaborate to organize and promote forums on how to improve this industry and realize its full potential.
\end{abstract}

\section{Keywords}

Beekeeping, Honey, Hive, Challenge, and Opportunity

\section{Introduction}

Ethiopia is one of the countries with a large honey- producing potential in Africa. The country is home to a rich flora and has Africa's greatest honeybee population due to its unique ecological and climatic circumstances [1]. The country's large and diversified botanical resources, together with favorable weather conditions, make it ideal for beekeeping. Around 10 million honeybee colonies exist in the country, with roughly 7 million kept in beehives by farmers and the rest living in the wild in the forests. Because of its large number of colonies, it is Africa's biggest honey and beeswax producer [2].

In Ethiopia, beekeeping is an essential part of the agriculture and rural development programs. At the household level, it plays a role in ensuring nutritional, economic, and ecological security to rural populations. Honey is useful as a food, medicine, and cash crop for both home and international markets [3]. According to this author, around 620,101 kg of honey was exported in 2010/2011, and the sale of honey generates an average of 420 million Ethiopian Birr per year. Beekeeping 
is a common activity among smallholder farmers and landless people since it does not require cultivated land, involves little investment, and yields immediate financial returns [4]. This sector has the potential to produce jobs for smallholders in both rural and urban parts of the country, by government strategy. According to Teshome and Megerssa [5], beekeeping employs two million Ethiopians. As a result, the development of beekeeping techniques is now widely recognized as one of the best ways to improve society's livelihood.

Ethiopia has the potential of producing 500,000 tons of honey and 50,000 tons of beeswax, according to various reports. Nega and Eshete [6] reported Ethiopian's annual total honey output reached 53,000 tons, which is less than $10 \%$ of the potential, while the country produces 3,800 tons of beeswax annually. According to these sources, around $80 \%$ of the total honey produced is used for local brewing known as Tej (honey wine), with the remainder being marketed as table honey in the domestic market or exported. Michael [7] reported the country produces about 54,000 tons of honey each year. CSA [8] also reported that the current production is estimated to be 58,000 tons however, FAO [9] data shows, honey and beeswax output reached 53,782 and 5,742 tons, respectively.

As various literature shows, even though the country has favorable environmental conditions for beekeeping, more opportunities, and a high potential for honey production, there are significant constraints that impede and keep this sector from realizing its potential for honey and beeswax production, earning foreign exchange, and providing income to smallholder beekeepers. As a result, there is a need to assess the constraints that are preventing this sector from reaching its full potential in the country. This document will aid in the development of a topic for improving honey production on a national or local level in general. Based on this, the objective of this paper is to determine the constraint and potential of beekeeping in Ethiopia.

\section{Materials and Methods}

This paper included a detailed evaluation of relevant information on beekeeping practices, as well as the constraints and opportunities that beekeeping presents in Ethiopia. Twenty-two more relevant papers were chosen based on relevant information from over thirty-two publishes papers. International journals, study reports, and reviews on honey production were included in the literature review. The data on honey and beeswax production was taken from the Federal Democratic Republic of Ethiopia's Central Statistical Agency (CSA, 2018/19) and the UN's Food and Agriculture Organization database (FOA, 2019).

\section{Economic Importance of Beekeeping in Ethiopia}

Beekeeping has long been a part of Ethiopia's farming systems [10]. It has been a tradition since long before other farming systems. It has been a tradition for a long time before other farming systems existed. Around one million farmers are expected to maintain bees, which is a long-standing and widely held activity in rural areas across the country. Beekeeping has played and continues to play, an important part in both the country's national economy and the subsistence smallholder farmers' livelihoods [11]. The socio-economic impact of beekeeping and the main hive products and importance of beekeeping are summarized as follows:

Honey production: Honey, a natural product of the honeybee, is a good source of energy because it includes simple sugars that are ready for digestion as soon as they enter the intestine. Honey is in high demand on the local market since it is used to make the traditional beverage 'Tej' (honey mead). Much honey has traditionally been fermented in Ethiopia to make 'Tej.' According to Sahle et al. [1], 85\% of the total honey estimated to be brought for the market is used for 'Tej' manufacture, with $15 \%$ of the total honey consumed at home. Furthermore, beekeepers are estimated to earn around 360-480 million Birr per year from the total honey produced in the country [3]. According to the report of FAO [9], from the 187 tons of honey exported about a 133million ET Birr Per year was earned at a national level.

Beeswax production: Wax is largely used in the production of comb foundations, cosmetics, candles, ointment and cream, varnishes and polishes, unique forms and surfaces for creative sculptures, and the fabrication of queen cups for the development and reproduction of bee colonies. In Ethiopia, traditional hives are used to collect wax rather than moving frame hives. Traditional hives' wax yield is estimated to be $8 \%-10 \%$ of the honey yield, compared to $0.5-2$ percent for frame hives [12]. Nonetheless, it is estimated that a significant amount of beeswax is lost at various stages due to a lack of awareness of its marketability. The annual beeswax production of the country is estimated at 5,790 tonnes and this makes the country is the second- largest beeswax producing country in the world after India [9]. It is a key exportable agricultural product that contributes to the national economy through foreign exchange revenues. According to the FAO [9] data, the yearly average value of beeswax exported is estimated to be over 325 tones, with a profit of around 560 million ETB (Figure 1). 


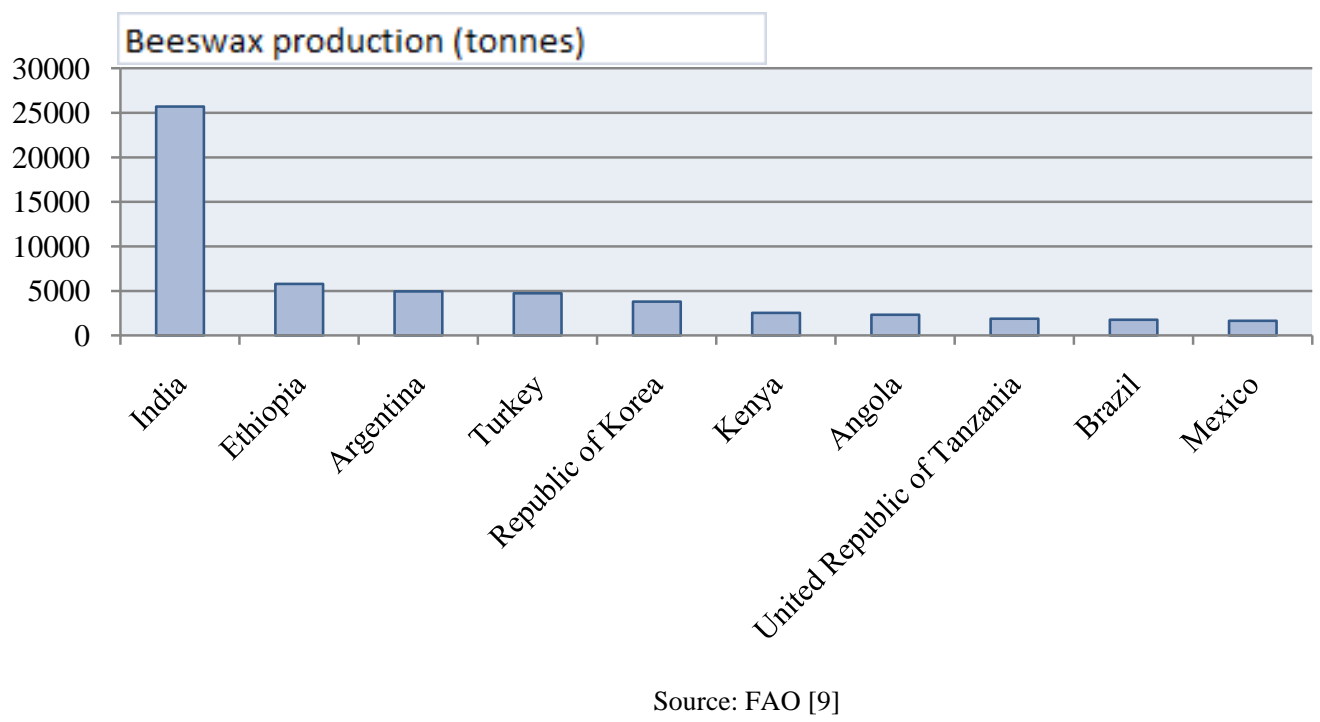

Figure 1. Top 10 beeswax production countries in the World 2019.

Crop pollination: Bees play an important role in the agricultural system. Although the importance of honeybees in agricultural pollination is underestimated, they play an important role in enhancing the national food supply and plant species regeneration. Honeybees are also thought to play an important part in Ethiopia's economy by providing pollination services. An experiment was done in Ethiopia to investigate the effect of pollination on Niger (Guizotia abyssinica), and the results revealed that honeybees increased Niger seed yield by about $43 \% .37$ and the onion (Allume Cepa) by a factor of two [2].

In addition to its economic relevance, beekeeping makes a major contribution to annual income supplementation. Farmers make money by selling hives or colonies, as well as honeybee products. Honey production and value addition to honey products are essential to poor people's long-term survival. It also plays a role in providing employment opportunities for landless men and women, as it requires little cash to get started. It is also important to note that a large number of people (intermediaries and traders) are involved in honey harvesting and distribution (at the village, district, and zonal levels).

\section{Beekeeping Practices in Ethiopia}

Honey is produced in practically every region of Ethiopia, with different types of honey produced in different areas. The majority of honey produced in the country $(92.80 \%$ of total honey produced) is produced by traditional beehives, which provide low yields and poor-quality honey. According to the result of the survey of CSA [8] revealed, from a total of 7.08 million hives estimated to be found in the country, the greater part (96.03\%) is reported to be traditional.

Ethiopia has a vast natural resource base that allows for the production of honey and other hive products, and beekeeping is still practiced in most parts of the country by beekeeper households [4]. According to Kassa and Megerssa [5], bees are currently handled using three unique beekeeping practices: traditional, transitional, and modern hive systems. Each production system is classified according to the technologies used and the system's productivity potential. A brief explanation below indicates different productivity statuses, types of inputs used, and manageability of each system (Table 1).

Table 1. Number of beehives, honey production, and average frequency of honey harvests per year in Ethiopia

\begin{tabular}{cccc}
\hline Type of beehive & No. of Beehives & Amount of honey produced (kg) & The average frequency of harvests/year \\
\hline Traditional beehives (Forest and backyard) & $6,794,424.00$ & $54,367,925.00$ & 1.59 \\
Intermediate/ transitional beehives & $80,164.00$ & $951,706.00$ & 1.62 \\
Modern bee- hives & $200,600.00$ & $3,268,521.00$ & 1.76 \\
Total & $7,075,188.00$ & $58,588,152.00$ & 1.60 \\
\hline
\end{tabular}

Source: CSA [8] 


\subsection{Traditional (Forest and Backyard) System}

Traditional beekeeping in Ethiopia's oldest and richest practice, having been practiced by the Ethiopian people for thousands of years. In practically every section of the country, several million bee colonies are handled using the same old traditional beekeeping practices [13]. Hive is made of locally available materials such as tree logs, bamboo, woven grasses, and other natural elements. Beekeepers that are knowledgeable and skilled in using these hives could perform many operations with less equipment [12]. Forest beekeeping and backyard beekeeping are the two forms of traditional beekeeping practices. Forest beekeeping, which involves hanging several traditional hives on trees, is popular in various parts of the country, particularly in the west and south. In most other parts of the country, backyard beekeeping is popular, with relatively better management.

The productivity of these hives is exceedingly poor, with an average yield of only 5-8 kg per colony per year, compared to 18-30 kg per year for improved hives (including transitional hives) [13]. Traditional beehives are relatively difficult to manage than transitional and modern hives because of colony inspection for brood status (e.g., for infectious diseases), opening hives at night, not suitable for managed queen rearing, higher risk for a variety of bees, and a queen being killed during operations, and honey harvesting is more difficult. Furthermore, colony feeding during times of food scarcity is challenging, and determining the maturity of honey before harvesting is pretty difficult.

\subsection{Transitional Beekeeping}

Transitional beekeeping practice was first introduced into Ethiopia in 1976. It is a form of beekeeping activity that falls somewhere between traditional and modern beekeeping, and it's one of the better methods of beekeeping when compared to traditional methods [4]. Kenya Top Bar Hive (KTBH), Tanzania Top Bar Hive (TTBH), and mud-block hives are the three types of hives used in this method. Because of its low cost and ease of construction, the KTBH has shown to be the most ideal. KTBH is well-known and widely used in different parts of the country among these hives. An ideal condition, a top- bar hive can produce approximately $50 \mathrm{~kg}$ of honey per year, but in Ethiopia, the average amount of crude honey produced per hive per year is $9-13 \mathrm{~kg}$ [2].

Transitional (intermediate) beekeeping has several advantages, including it is opened quickly and easily, the bees are guided into building parallel combs by following the line of the top bars, the top bars are easily removable, allowing beekeepers to work quickly, easier to construct than frames, and honeycombs can be removed from the hive for harvesting without separating themselves from the hive. This practice has its own set of drawbacks, such as the fact that top bar hives are more expensive than traditional hives, and that combs suspended from top bars are more likely to break off than combs built within frames [13].

\subsection{Improved beekeeping practices}

To provide optimal honey yield for a long time without damaging bees, modern beekeeping procedures are essential. The modern movable-frame hive is made up of properly built rectangular box hives placed one on top of the other in a tier, with the number of boxes varying depending on the size of the bee population and the season. Since 1970, around five different types of mobile frame hives have been introduced in Ethiopia [4]. Brood chamber, super (honey chamber), inner and exterior cover are all components of improved beekeeping hives. The improved box hive has an advantage over the others in that it produces a high quality and quantity of honey. Another advantage of an improved box hive is the ability to manage to swarm by supervising the bees as they look for honeybee flowers and pollination services. The downsides, on the other hand, are that the equipment is somewhat expensive, it requires experienced labor, and that it requires very specific precautions.

\section{Constraints and Opportunity of Beekeeping in Ethiopia}

\subsection{Constraints of beekeeping}

In Ethiopia, the beekeeping sub-sector has some key challenges and constraints that must be solved if the full potential of apiculture is to be realized.

Honeybee pests, predators and disease: With the life of bees, the number of pests and predators is remarkable. According to a study conducted by Malede et al. [14] ants, insects, spiders, snakes, and lizards, wax moth (Galleria mellonella), bee-eater birds, bee lice (Braula coecal), honey badger (Mellivora capensis), monkey, and small hive beetles (Ae- 
thina tumida) cause devastating damage to honey bee colonies and products in a short time. Honey bees, on the other hand, can become affected by the disease, posing a major threat to honey bee production and productivity. Different authors investigated and reported on the existence of two adult honeybee illnesses, Melpighamoeba mellificae and Nosematosis, as well as their distribution [11]. The most commonly known honeybee diseases reported to exist in Ethiopia are Nosema, Amoeba, and Chalkbrood diseases [13].

Improper application of agrochemical inputs: Agrochemical poisoning, a lack of equipment, pests, and predators have been highlighted as the main three difficulties facing the beekeeping business, with about three-quarters of beekeepers losing their colonies due to sprayed agrochemicals [15]. Improper pesticide use in crop production is a source of socio-economic conflict among farmers, and poisoning of honeybees by these chemicals has increased over time, with some beekeepers losing all of their colonies as a result of agrochemical use. According to a study conducted by Bizuayehu in the east and west Gojjam Zones of the Amhara Region, on average, 1,736, 4036, and 1,890 honeybee colonies die, abscond, and dwindle each year [16]. This suggests that the application of various insecticides on crops has a significant impact on beekeepers' bottom lines.

High cost and limited availability of improved technologies: Dependence on traditional and low technology input, poor pre-and post-harvest management, insufficient extension services, and weak marketing infrastructure are the key problems influencing the promotion and development of honey production and marketing. According to Seid and Solomon [12], Introducing upgraded hives and working tools to the rural population is out of reach for most farmers and even for those who can afford it, it is not readily available. Some beekeepers, for example, have modern beehives (only boxes) but lack the instruments needed to properly manage them (such as a smoker, queen excluder, or honey extractor) [17]. Other reports indicated that in some parts of the country the modern hive constructed by some private companies and cooperatives are constructed with wrong dimensions and made of poor quality timber. As a result, the migration rate of honey bees in the modern hive is very high [1].

Limited technical capacity: Limited technical capacity, such as a shortage of materials and the ability to construct improved beehives, inadequate hive management skills, limited know-how in regards to hive colonization, insufficient capacity for monitoring beehives for pests and illnesses, and limited capacity for developing solutions to problems such as additional feed and disease management, are all important challenges to the sector's development. One of the biggest concerns has been the occurrence of infections such as parasites, bacterial, and viral diseases. Furthermore, predators and the unrestricted use of pesticides and herbicides are two important difficulties that have an impact on the quality and wholesomeness of honey bee products. Moreover, understanding is scarce about how to mitigate and reduce the primary risks associated with apiculture, as well as how to manage them when they arise. Beekeepers that do have modern beehives lack the necessary skills and knowledge to effectively manage them, and training is not widely available. As a result, they frequently use poor extractive harvesting methods and tools that are inappropriate for this kind of hive. Moreover, during droughts, they rarely offer supplementary feed (water, sugar syrup, or flour) and have little awareness of existing honey-quality requirements in export markets [17].

Lack of financial resources (access to financial service): Access to financial services is one of the primary obstacles to increasing honey production. Poor financial access has been a major barrier to the development of industrial-scale production and the establishment of honey processing and packaging operations [18]. Beekeepers have limited access to financial services that would allow them to upgrade from traditional beehives to better versions, making it difficult for them to buy modern beehives and other tools necessary to increase honey production. Most beekeepers do not have the financial means to upgrade to transitional and modern beehives; therefore they continue to produce honey using traditional methods [17].

Lack of standardization and quality management system: On the farm, there is a lack of standardization and quality management systems, which contributes to poor production, processing, packaging, and labeling. This is due to a lack of adequate laboratories and facilities for quality assessment. This has an impact on access to international markets, as well as the production and sale of honey on the domestic market and along the value chain [19]. In absence of support to address proper handling, packaging, and labeling, locally produced honey fails to command good market prices even though it is organic and free from human interferences, making it inherently a premium product attract to niche markets. Locally produced honey fails to attract excellent market pricing in the absence of support to meet proper handling, packaging, and labeling, although it is organic and lacks human interferences, making it naturally a premium commodity attracting to niche markets.

Limitation in business management: Most beekeepers consider beekeeping as a part-time business with low work re- 
quirements. One of the biggest issues that beekeepers face is managing and growing their businesses. The majority of profits are not re-invested in the business to increase production and improve quality standards. Processors, particularly large marketing agencies, demand an assured supply of a specific quantity and quality. As a result, beekeepers are unable to compete in competitive markets where their products could command a higher price. Beekeepers lack established commercial procedures, and there are few connections between smallholder, medium-scale, and large-scale producers and processors. Low production, poor yield, limited market access, low incomes, and under-utilization of beekeeping for wealth generation are the overall effects of the above issues [20].

\subsection{Opportunities of beekeeping in Ethiopia}

There are tremendous opportunities in the honey industry for the improvement of the livelihoods of people in the country.

Diverse Agro-ecological conditions and flowering plants: The country's current various agro-ecological conditions are ideal for honey production. The favorable environmental conditions encourage the establishment of dense forests such as rainforests, dry deciduous forests, spiny woods, and other forms of flora that are conducive to beekeeping and honey production. There are also a lot of marginal lands, such as dry and semi-arid places, that can't support permanent or intense agriculture without a lot of money invested inland. Beehives could be placed in this area because the bees will not be relying on the land directly, but rather on the nectar flowers found in the marginal regions [10]. Ethiopia has beekeeping potential due to the abundance of diverse plants and crops that provide nectar and pollen for honey bees. There are around 7,000 varieties of flowering plants in the country that the bees feed on and collect crucial raw materials for making honey and other hive products [13].

Existence of strong bee colonies: Ethiopia's ideal climatic conditions and diverse floral resources enable the country to support around 10 million honeybee colonies, of which 7 million are kept in local beehives by farmers and the remainder live in the wild in the forests. Similarly, data on beehives acquired during the CSA [8] livestock survey revealed that there are an estimated 7.08 million hives in the country's rural areas. As a result, the country has the largest number of bee colonies in Africa.

Demand for the bee products and honeybee: The demand for bee products is expanding at an alarming rate both in the domestic and international markets. According to the healthy state of bees and the production of organic honey are in great demand [10]. Beekeeping is an environmentally friendly activity that can be integrated with other agricultural practices such as crop production, animal husbandry, horticultural crops, and natural resource conservation. As a result, it would be one of the most critical intervention areas for long-term growth. Beekeeping contributions to poverty reduction, sustainable development, and natural resource protection have been well recognized and underlined by Ethiopia's current government and Non-Governmental Groups (NGOs).

Bee products are in high demand, and this trend is expected to continue. Honey has a lot of health benefits, so it's in great demand. Honey and its derivatives are commonly used inputs for cosmetics and medicine production and formation; widely used inputs for cosmetics and drug manufacturing and formulation. Currently, approximately all of these industries' supplies come from imports because local suppliers do not meet the industry's quality standards. Import substitution presents a significant potential.

Presence of indigenous knowledge, skills, and interest in improved technologies: In southwest Ethiopia, beekeeping is a traditional activity passed down from father to son. Hive construction from locally available materials, swarm catching; hive fumigation, honey and swarming season identification, different medicinal values of honey, identification of important honeybee floras, and identification of adulterated honey are the main areas of indigenous beekeeping knowledge [13]. This experience and pride in beekeeping may help to speed up adoption among new beneficiaries. According to research conducted by Dinku and Bereket in Hawassa city and Tsegayet in Wolaita and Dawro Zone beekeepers in Southeastern Ethiopia have good indigenous knowledge of traditional beekeeping [19, 21].

The presence of supporting organization: Various governmental and non-governmental organizations (NGOs) were active in beekeeping practice, for example, they provided financial credit, beehives, and bee equipment, and they gave short-term beekeeping training. Training has resulted in significant improvements in apiculture production. For the past ten years, new technologies, equipment production, and distribution, and institutional capacity building have been deployed. Training of extension workers and farmers in apiculture has also been prioritized for them to get better beekeeping knowledge and develop skills, allowing them to improve traditional beekeeping practices and increase honey and beeswax production [22]. 
The government has increased its attention to developing the apiculture subsector as one of its strategies for poverty reduction and diversification of export commodities by linking them with local carpenters who produce modern beehives and creating market links to the final consumers, including the foreign market. The government was currently promoting a self-contained watershed development initiative that includes beekeeping. Low-cost modern hives are being built with locally accessible materials, and efforts are being made to organize farmers into groups and link them with local carpenters who build modern beehives. Recent initiatives by the public and private sectors, as well as Non-Governmental Organizations (NGOs), are moving in the right direction in terms of improving the apiculture sub sector's to exploit its potential and increase its overall competitiveness by introducing and promoting modern hives to obtain high-quality honey for industrial processing.

\section{Conclusion and Recommendations}

The beekeeping sub-sector plays an important role in increasing and diversifying the income of subsistence Ethiopian smallholder farmers, particularly those with small plots of land and those who are landless. It also contributes a lot to the country's national economy. Apiculture has a lot of room for expansion; increases output to fulfill the ever-increasing demand for the product. The country's diversified agro ecological characteristics are ideal for honey production. However, other issues are impeding the sector's growth. Bees and other commercial insects have been killed as a result of the indiscriminate use of pesticides and insecticides Bee mortality would have a significant impact not just on honey production, but also on crop yields and plant life that rely on pollination by bees. Production and processing equipment, as well as infrastructures such as transportation, clean water, communication systems, and buildings, are all required for a successful beekeeping business. However, the sector faces significant difficulties due to a shortage of or insufficient supply of these resources. Therefore;

$>$ It is important to harmonize policy and supportive structures at the regional and national levels to guide the development of the beekeeping sector.

$>$ To improve the productivity of this sector in the country, there is a need for effective and efficient organization, funding, research and development, extension program that are market-focused.

$>$ Conservation, protection, and maintaining the existing honey bee colonies for the future are very important.

$>$ Policy and regulations that are specifically designed for the beekeeping sub-sector, to regulate the use of pesticides and insecticides should be there and applicable.

$>$ Agrochemicals should be used in ways that do not harm bees.

$>$ The existing production techniques need to be diversified and improved to ensure proper beekeeping husbandry to reach optimal production capacity.

$>$ Training on beekeeping and its management (including pests and diseases management, bee forage development, colony management, honey harvesting, extraction, processing, etc should be undertaken.

\section{Acknowledgements}

I would like to express my deepest gratitude to Dr. Xibabu Manaye and Dr. Takele Wakaro for their suggestions, comments and advice. I also thank my friends who give information, guidance, comments and suggestions.

\section{References}

[1] Sahle, H., Enbiyale, G., Negash, A., Neges, T. (2018). Assessment of honey production system, constraints and opportunities in Ethiopia. Pharm Pharmacol Int J., 2018, 6(1): 42-47.

[2] Hailemichael Tsehaye Bahta. (2018). The Status of beekeeping practices and honey production system in Ethiopia: A review. Int J Eng Develop Res., 2018, 6(2): 581-585.

[3] Amsalu Arega, Hailu Mazengia, Muse Haile melekot. (2020). Apiculture constraints and opportunities in Diga and Wayu Tuka Districts, East Wollega Zone, Oromia National Regional. International Journal of Advanced Research in Biological Sciences, 2020, 7: 21-33.

[4] Dekebo, A., Bisrat, D., Jung, C. (2019). Opportunities and constraints of beekeeping practices in Ethiopia. J of Api., 2019, 34(2): 169-180.

[5] Kassa Degu, T., Regasa Megerssa, G. (2020). Role of beekeeping in the community forest conservation: Evidence from Ethiopia. Bee World, 2020, 97(4): 98-104. 
[6] Nega, T., Eshete, Y. (2018). Review of Ethiopia's global position in honey and other bee products production and marketing: Analysis of sectoral opportunities and limitations. Biomed J of Sci \& Tech Res., 2018, 10(3): 7879-7883.

[7] Michael Kiingwa Kiiti. (2019). Socio-Economic, cultural and institutional factors influencing modern box hives adoption in Kitui County, Kenya. 2019.

[8] CSA. (2019). Central Statistical Agency: Agricultural Sample Survey, Volume Ii Report on Livestock and Livestock Characteristics. 2019.

[9] FAO. (2017). Food and Agriculture Organization: Livestock Primary. 2017

[10] Kenesa Teferi. (2018). Status of beekeeping in Ethiopia: A review. Dairy and Vet Sci J., 2018, 8(4): 555743.

[11] Fikru, S. (2015). Review of honey bee and honey production in Ethiopia. J of Ani Sci Advances, 2015, 5(10): $1413-1421$.

[12] Guy, S., Legesse, S. (2015). Review on beekeeping activities, opportunities, and challenges. J Harmoniz Res Appl Sci., 2015, 3(4): 2004-010214.

[13] Ababor, S., Tekle, Y. (2018). Beekeeping practice, opportunities, marketing and challenges in Ethiopia: Review. Dairy and Vet Sci J., 2018, 5(3).

[14] Birhan, M., Sahlu, S., Getiye, Z. (2015). Assessment of challenges and opportunities of bee keeping in and around gondar. Aca J of Entomol, 2015, 8(3): 127-131.

[15] Fikadu, Z. (2020). Pesticides use, practice and its effect on honeybee in Ethiopia: A Review. Int J of Tropi Insect Sci., 2020, 40(3): 473-481.

[16] Ayele, B., Jenberie, A., Haylemelekot, M., Ayalew, W. (2020). Side effects of agro-chemicals on beekeeping in East and West Gojjam Zones of Amhara Region, Ethiopia. Adva in Biosci and Bioeng, 2020, 8(3): 47.

[17] Tekle, G., Weldeyohanis, S. (2016). Review on challenges and opportunities of honey marketing in Ethiopia. J of Market \& Cons Res., 2016, 23: 33-37.

[18] Mamo, Y. S. (2016). The honey industry in comesa: Opportunities and challenges. Bulletin of Animal Health and Production in Africa, 2016, 64(1): 207-216.

[19] IBAR. (2016). Inter-African Bureau for Animal Resources. Special Edition 2016: Honey Production, Bee Health, and Pollination Services African; The Honey Industry In Comesa: Opportunities And Challenges, Bulletin of Animal Health and Production in Africa 2016.

[20] Negash, D., Mengeste, B. (2019). Assessment of honey production system, constraints and opportunities in selected kebeles of Hawassa City administration, Ethiopia. Int J of Res Granthaalayah, 2019, 7(8): 78-87.

[21] Lijalem, T., Zereu, G., Tebeje, M. (2017). Opportunities and constraints of beekeeping in Wolaita and Dawro Zones, Southern Ethiopia. Afri J of Agri Res., 2017, 12(18): 1587-1592.

[22] Mitikie, A. (2017). Characterization of beekeeping system and evaluation of honey quality in Tehulderif District of the South Wollo Zone, Amhara Region, Ethiopia. 2017. 